\title{
Study use of Antiepileptic Drugs in Pediatric Ward at GMERS Hospital, Gandhinagar, India
}

\author{
Princy Christian ${ }^{1, *}$, Janki Patel ${ }^{1}$, Shrikalp Deshapande ${ }^{2}$, Seema Shah ${ }^{2}$ \\ ${ }^{1}$ Department of Pharmacology and Pharmacy Practice, K.B Institute of Pharmaceutical Education and Research, \\ Gandhinagar, Gujarat, INDIA. \\ ${ }^{2}$ Department of Pediatrics, GMERS, Gandhinagar, Gujarat ,INDIA.
}

\begin{abstract}
Introduction: Epilepsy, a common neurological disorder characterised by a transient paroxysm of neuronal discharge and the condition seizure disorder is reported majorly among pediatric population. Around 4-10 \% of children suffer atleast 1 seizure in their first 16 years of life. It includes febrile convulsion (typical or atypical), epilepsy or any neurological disorder. Anti-epileptic drugs are the primary therapeutic measure to control seizure and manage epilepsy. To determine rationality of therapy, it is necessary to have knowledge on how drugs are prescribed and used to treat a particular disease or a group of diseases in the clinical setting and so due to paucity of data on anti-epleptic drugs usage amongst pediatric population in India, drug use study was conducted. Objectives: The study aims to determine the utilization pattern of anti-epleptic drugs in in-patient admission in pediatric wards of GMERS Hospital, Gandhinagar. Materials and Methods: The study was a prospective observational cross sectional study which was conducted for a period of 4 months. Data of 132 pediatric patients prescribed with anti-epleptic drugs by were enrolled and the resource used to collect data included subjects case notes which was recorded on a pre-structured data collection form. Utilization pattern of anti-epleptic drugs was assessed based on socio-demographic variables, clinical profile, therapy and newer and conventional drugs. Results: Total 1687 patients were admitted, out of which 132 were prescribed with anti-epleptic drugs. Majority of anti-epleptic drugs were prescribed in 2-12 years age group (59\%) and in boys (56\%). Febrile convulsion $(40 \%)$ being the most commonly diagnosed condition followed by epilepsy $(29 \%)$ amongst the study population. Midazolam were administered to 113 patients $(41 \%)$, being the most frequently prescribed benzodiazepine the frequently used dual therapy was midazolam + phenytoin followed by midazolam + clobazam. The most used triple therapy was midazolam + phenytoin + sodium valproate. Conclusion: Phenytoin was the most used anti-epleptic drugs and midazolam was the most used benzodiazepens Midazolam monotherapy was used as a first line drug for management of seizure attack. If seizure was not controlled with midazolam then phenytoin was added. Conventional anti-epleptic drugs were used more as compared to newer AEDs.
\end{abstract}

Keywords: Epilepsy, Drug utilization, Seizures, Anti-epileptics, Paediatrics.

\section{INTRODUCTION}

Epilepsy is a chronic non-communicable disease of the brain that affects around 50 million people worldwide. ${ }^{1}$ It is characterized by recurrent seizures, which are brief episodes of involuntary movement. Around $4-10 \%$ of children suffer at least one seizure in the first 16 years of life. The incidence is highest in children below 3 years of age with a decreasing frequency in older children. ${ }^{2}$

WHO, in 1977 defined Drug utilization research (DUR) as "The marketing, distribution, prescription and use of drug in the society, with special emphasis on the resulting medical, social and economic consequence. ${ }^{3}$ The primary aim of drug utilization research being rational use of drug in population or health care facilities or country which can be attained by means of measuring behaviour of health care facilities with the use of core and complimentary indicators that help rectifying the drug use pattern, detecting traditional use of drugs, intervention to improved drug use and help policy makers in drug supply and costing. ${ }^{4}$
DOI: 10.5530/ijopp.13.2.27

Address for correspondence: Princy Raju Christian, Pharm.D Intern, Department of Pharmacology and Pharmacy Practice, K.B Institute of Pharmaceutical Education and Research, Gandhinagar, Gujarat, INDIA. Phone no: +91-7600517749 Email Id: princyraju.3454@ gmail.com

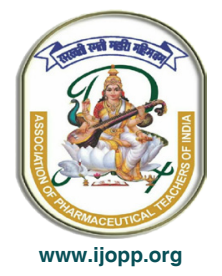


Management of epilepsy is primarily based on the use of antiepileptic drugs. The antiepileptic drugs are categorized into conventional drugs and newer drugs. Conventional drugs include valproic acid, phenytoin, carbamazepine, phenobarbital and primidone. Newer drugs include lamotrigene, topiramate, levetiracetam, oxcarbazepine and gabapentin. Benzodiazepines like midazolam, clonazepam, diazepam, clobazam are used as an add-on therapy. ${ }^{5}$ Conventional drugs are highly used as compared to newer drug because it is less expensive. ${ }^{6}$

\section{MATERIALS AND METHODS}

The study was a prospective observational cross sectional study which was conducted in IPD Ward for a period of 4 months at the GMERS hospital, Gandhinagar. Out of 1687 data of 132 pediatric patients prescribed with AEDs by were enrolled and the resource used to collect data included subjects case notes which was recorded on a pre-structured data collection form.

\section{Inclusion criteria}

- All the prescriptions containing antiepileptic drugs written and used at medical ward site for in patient.

\section{Exclusion criteria}

- Discharge medication order.

- Out-patients prescription or prescription of patients who are not admitted at the study site.

The enrolled patients were thoroughly explained about the nature and purpose of the study. Inform consent form (ICF) was obtained by the parents. following to that data were collected by using case notes, nursing charts of the patients in a designed data collection form to record all the necessary details like demographic details, complaints, diagnosis, time and duration of seizures, total number of drugs and medication chart.

\section{Statistical Analysis}

Collected data will be treated in MS office, excel 2007, windows 7 equal or higher and will be expressed as an absolute number, with or without percentage or as mean with standard deviation or as median with ranges. Frequency comparison, mean comparison will be performed by a suitable statistical test of probability value of less than 0.05 will denote statistical significance.

\section{RESULTS}

Our study described prescribing pattern and drug use of a total of 132 subject medical records that were observed and followed up in this prospective study at GMERS Hospital Gandhinagar for duration of 4 months. Total 1687 patients were admitted during the study period in paediatric ward of which data of total 132 patients from IPD who were enrolled using inclusion and exclusion criteria was collected. The prevalence of seizure attack in patients admitted in IPD was found to be $7.82 \%$ who were administered a single or multiple doses of antiepileptic drugs.

The mean age (SD) of patients having seizure episode was 4.754 (4.32) with a range of 0 to 18 years. Pediatric age group was divided into 5 groups as birth to 1 month, 1 month to 2 years, 2 years to 12 years, 12 years to $<16$ years and 16 to 18 years.

On categorization of study subjects according to age reveals that $59 \%$ patients fall into category of children, $29 \%$ under infants and $10 \%$ of patients were adolescents in AED usage. The AEDs were highly prescribed in the age group of 2-12 years.

In Figure 1, Distribution of patients according to gender is shown that number of boys and girls were $74(56 \%)$ and $58(44 \%)$ respectively. Thus it was seen that boys were prescribed more frequently with AED as compared to girls. And of the total 132 patients admitted during the study period $50(38 \%)$ patients have had a previous seizure attack in the past or are a known case of epilepsy (Figure 2).

As mentioned in Table 2, 24(63\%) patients were diagnosed with febrile convulsion in the age group of 1 month to 2 years, while in the age group of 2-12 years, $29(38 \%)$ patients were diagnosed with febrile convulsion and $26(34 \%)$ patients with epilepsy. In the age group 12 to $<16$ years, $8(62 \%)$ patients were diagnosed with epilepsy.

Table 3 shows different AEDs used in pediatric department. Midazolam was administered to 113 (41\%)

Table 1: Age wise distribution of subjects prescribed with antiepileptic drugs in pediatric department of GMERS hospital, Gandhinagar during study period.

\begin{tabular}{ccc}
\hline AGE GROUP & $\begin{array}{c}\text { NO. OF PATIENTS } \\
\text { (N) }\end{array}$ & $\begin{array}{c}\text { PERCENTAGE } \\
(\%)\end{array}$ \\
\hline 1 month to 2 years & 38 & 29 \\
2 years to 12 years & 78 & 59 \\
12 years to $<16$ & 13 & 10 \\
years & 3 & 2 \\
16 years to 18 years & 132 & 100 \\
\hline
\end{tabular}




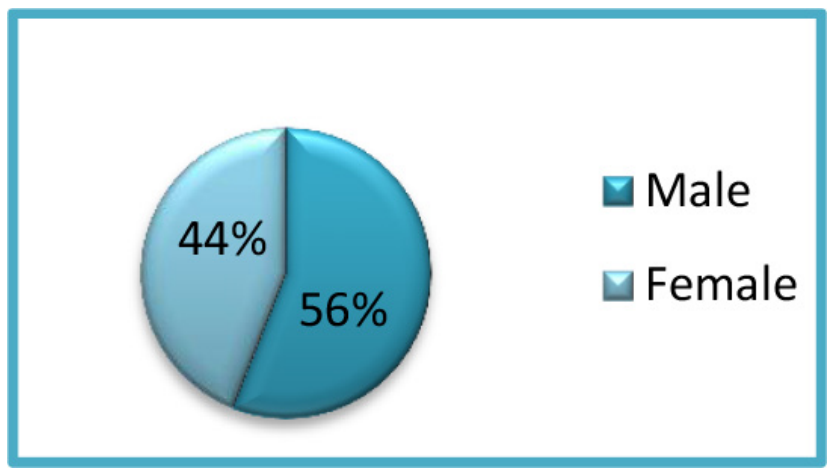

Figure: 1 Distribution according to the Gender.

\begin{tabular}{|c|c|c|c|c|c|}
\hline \multirow[t]{2}{*}{ Diagnosis } & \multicolumn{4}{|c|}{ Age } & \multirow[t]{2}{*}{ Total } \\
\hline & $\begin{array}{c}1 \\
\text { month } \\
\text { to } 2 \\
\text { years }\end{array}$ & $\begin{array}{c}2 \text { years } \\
\text { to } 12 \\
\text { years }\end{array}$ & $\begin{array}{c}12 \text { years } \\
\text { to }<16 \\
\text { years }\end{array}$ & $\begin{array}{c}16 \text { years } \\
\text { to } 18 \\
\text { years }\end{array}$ & \\
\hline $\begin{array}{c}\text { Febrile } \\
\text { convulsion }\end{array}$ & 24 & 29 & 0 & 0 & $53(40 \%)$ \\
\hline Epilepsy & 3 & 23 & 8 & 1 & $38(29 \%)$ \\
\hline Convulsion & 7 & 12 & 2 & 0 & $21(16 \%)$ \\
\hline GTCS & 1 & 3 & 1 & 1 & $6(5 \%)$ \\
\hline $\begin{array}{l}\text { Unprovoked } \\
\text { seizures }\end{array}$ & 1 & 4 & 0 & 0 & $5(4 \%)$ \\
\hline $\begin{array}{l}\text { Status } \\
\text { epileptics }\end{array}$ & 0 & 1 & 1 & 0 & $2(2 \%)$ \\
\hline Others & 2 & 3 & 1 & 1 & $7(5 \%)$ \\
\hline
\end{tabular}

Table 3: Different drugs prescribed in paediatric department of GMERS hospital, Gandhinagar during study period.

\begin{tabular}{ccc}
\hline Name of Drug & No. of Patients & Percentage \\
\hline Midazolam & 113 & $41 \%$ \\
Phenytoin & 70 & $25 \%$ \\
Sodium Valproate & 35 & $13 \%$ \\
Levetiracetam & 5 & $2 \%$ \\
Clobazam & 37 & $13 \%$ \\
Phenobarbitol & 10 & $4 \%$ \\
Carbamazepine & 5 & $2 \%$ \\
Clonazepam & 1 & $0.75 \%$ \\
Diazepam & 2 & $1 \%$ \\
Lacosamide & 1 & $0.75 \%$ \\
\hline
\end{tabular}

patients followed by clobazam in $37(13 \%)$ patients and diazepam in $2(1 \%)$ patients. Phenytoin was the most used AED in 70 (25\%) patients followed by sodium valproate in $35(13 \%)$ patients, phenobarbital in $10(4 \%)$ patients, levetiracetam and carbamazepine in $5(2 \%)$ patients.

Table 4 summarizes the overall AED utilization pattern

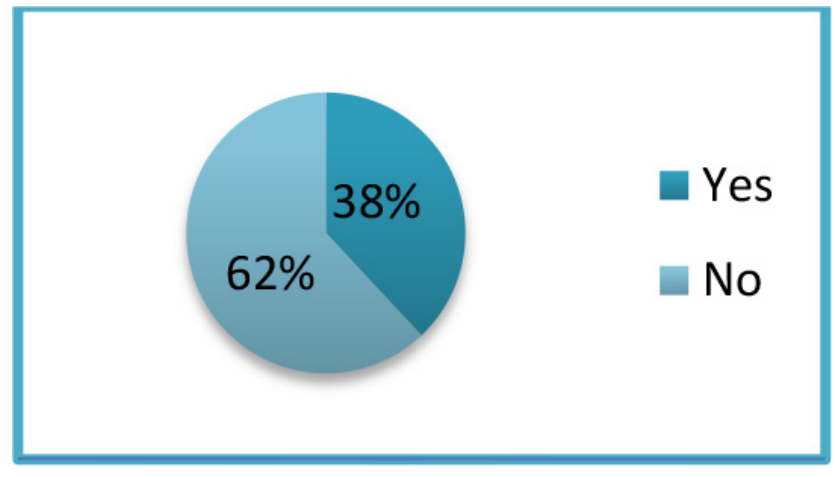

Figure: 2 Patients with the history of seizures.

among the study subjects.

The most commonly prescribed AED in monotherapy was phenytoin, followed by sodium valproate and BZD was midazolam followed by clobazam. The frequently used dual therapy was midazolam+ phenytoin followed by midazolam+clobazam. The most used triple therapy was midazolam+ phenytoin +sodium valproate.

\section{DISCUSSION}

This study includes results of a total 132 study subjects whose medication order with AED have been analyzed for socio-demographic variables of subjects, disease condition diagnosed and used to assess drug utilization pattern of AEDs in the in-patient hospital setting of Pediatric Department in GMERS Gandhinagar. This study was designed and carried out with the intent of updating the data presented by other similar studies that have been carried out in pediatric population of India in the past.

The present study shows that major incidence of seizure attack 59\% occurs in the age group 2-12 years (children), which eventually showcased use of AED in children maximally, that correlate with results of a study conducted by Bhojan $\mathrm{C}$ et al. in India which revealed that seizure and epilepsy affects children and infants more than any other age group. ${ }^{7}$ This indicates the study population was characterized by children and infants because of which lack of peak was seen in juvenile subjects and newly born children. Distribution of age has critical importance in DUS as it gives idea whether treatment differs according to different age group.

The demographic data of our study divulged that $56 \%$ patients were boys while the remaining 44\% were girls, thus boys were prone to seizure attack which is in accordance with a study done by CH Lakshmi Prathyusha et al. in India divulged that $73.24 \%$ male patients are predominance of female $26.76 \%$. It has been proven 
Table 4: Overall AEDs utilization for the treatment of seizure episode inpediatric ward.

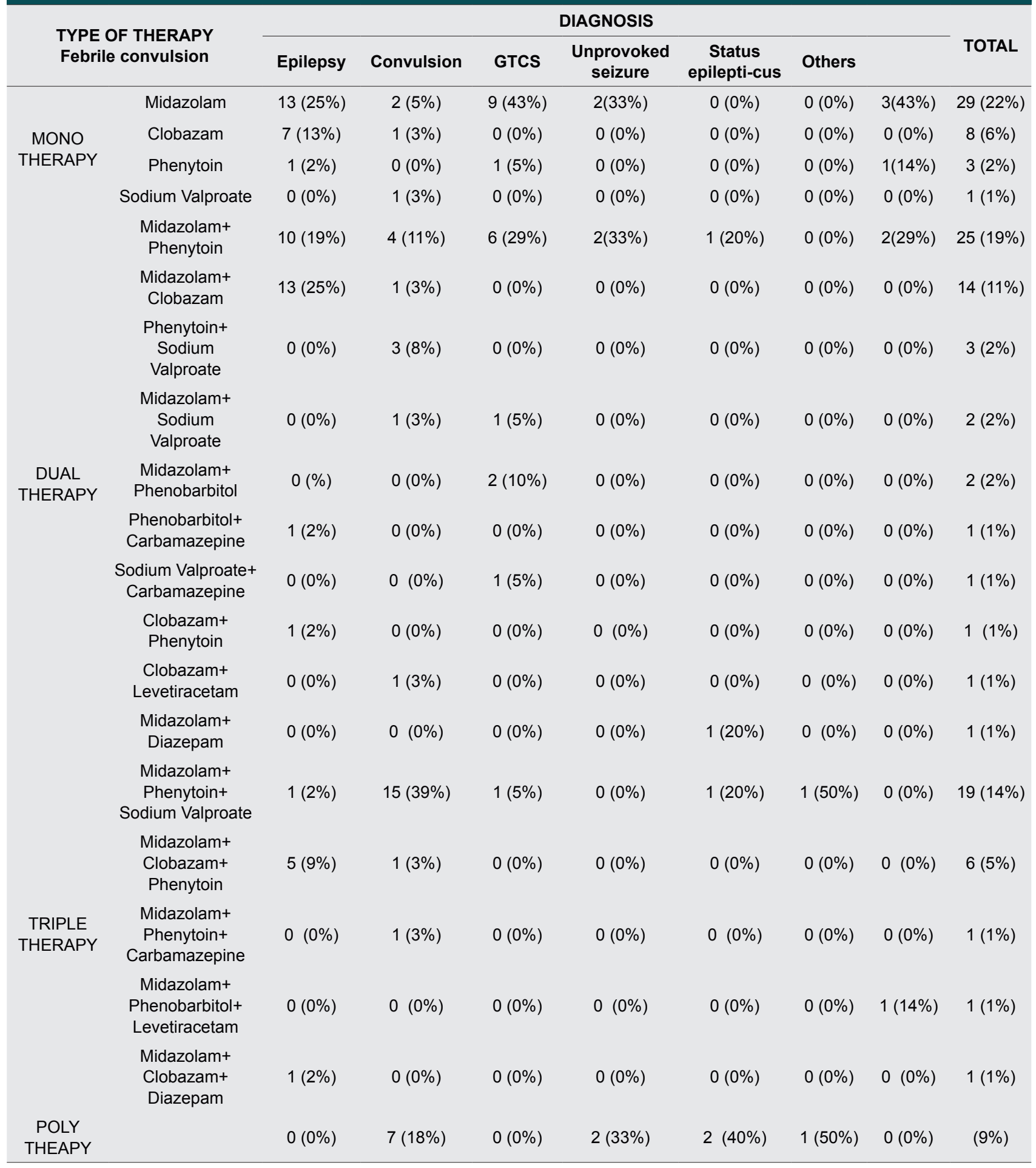

scientifically that female sex hormones (estrogen and progesterone) affect the threshold of seizures to some extent which leads to the difference. ${ }^{1,5}$

According to study results most of the patients had been admitted in the study because of fever followed by seizure as the chief complaint that was confirm Indian Journal of Pharmacy Practice, Vol 13, Issue 2, Apr-Jun, 2020 diagnosed as febrile convulsion $40 \%$ by visiting physician in the respective wards. The result of this study varies from another study performed in India. It is difficult to compare results of this study as a standardized system of classification is not implemented to classify seizures in Asia and due to lack of imaging and EEG testing to diagnose seizure and epilepsy types, thus due to 
absence of standardized system to classify seizures led to general classification in this study. Literature states that hyperthermia induces secretion of fever mediators including IL-B which contributes to generalization of febrile seizure that last for 10-15 min. Febrile seizures are seizure or convulsions that occur in young children and are triggered by fever. Young children between the age group 6 month and 5 years old are most likely to experience febrile seizures.

Studying the drug utilization pattern of AEDs showed that midazolam $41 \%$ was the most commonly prescribed drug in majority of patients followed by phenytoin $25 \%$ and sodium valproate $13 \%$. This was in contrast to a study based in a tertiary care teaching hospital by George J et al. were there was slight predominance 19.51\% of phenytoin prescribed for study patients and $17.88 \%$ sodium valproate prescribed for study participants to treat epilepsy. ${ }^{8}$

In our study we found that midazolam $25 \%$ was highly prescribed mono-therapy for febrile convulsion followed by dual-therapy of midazolam + phenytoin $19 \%$. In patients with epilepsy, triple-therapy of midazolam + phenytoin + sodium valproate was majorly used. Patients diagnosed with convulsion were treated mainly with midazolam $43 \%$, followed by dual-therapy of midazolam + phenytoin 29\%. In patients with GTCS, mono-therapy of midazolam $33 \%$, dual-therapy of midazolam + phenytoin 33\% and poly-therapy $33 \%$ was equally used. Triple-therapy $50 \%$ and poly-therapy $50 \%$ was used for management of status epilepticus. This result was in contrast to the study by Rishe $\mathrm{W}$ et al. which revealed that Phenobarbitone $1.3 \%$ was the most used monotherapy for management of partial seizures. In patients with generalized seizures, the most used monotherapy was Phenobarbitone $46 \%$ followed by dual therapy of phenobarbitone+phenytoin $19.4 \%$. Polytherapy was not used for management of any type of seizure. ${ }^{?}$

\section{ACKNOWLEDGEMENT}

Firstly, I want to thank my Guide Dr. Shrikalp Deshpande, Principal In-charge, KBIPER and co-guide Dr. Janki Patel for sharing their wisdom with me during the course of this project and for the constant advice, support and a thorough guidance which aided in the timely completion of this work. I express my heart filled gratitude to our mentor Dr. Seema Shah (Assistant Professor, Department of Pediatrics, GMERS Medical College, Gandhinagar) for her valuable advice, opinions and for being available whenever I needed them. I am immensely grateful to GMERS hospital for giving me permission to conduct this project. A very special gratitude goes to K.B. Institute of Pharmaceutical Education and Research for helping and providing the funding for the work.

\section{Funding}

K. B Institute of Pharmaceutical Education and Research.

\section{CONFLICT OF INTEREST}

The authors declare no conflicts of interest.

\section{Ethical approval}

The study was approved by the Institutional Ethics Committee and GMERS ethics committee.

Reference no: GMERS/MCG/IEC/45/2018

\section{ABBREVIATIONS}

AEDs: Anti-epileptic drugs; BZD: Benzodiapenes; DUR: Drug utilization research; DUS: Drug utilization Study; EEG: Electroencephalography; GTCS: Generalized Tonic-Clonic Seizures; ICF: Inform consent form.

\section{SUMMARY}

This study was a prospective observational cross sectional study which was conducted for a period of 4 months in a paediatric ward. Protocol, CRF and Consent form were designed. Ethics committee approval was obtained from GMERS and KBIEC ethics committee. Total 1687 patients were admitted during the study period in paediatric ward of which data of total 132 patient's data were collected according to the exclusion and inclusion criteria. Collected data were documented in a designed CRF. At the end of the study expected results were obtained. Future aspect of this study was to emphasize drug use evaluation to evaluate dosing, dosage regimen and short or long term side effects of drugs.

\section{REFERENCES}

1. Lakshmi PCH, PallaviC, Dr. Mahesh KVP, Chidambranathan S. Study on antiepileptic drugs used in children to treat various types of epilepsy in tertiary care hospital. International Journal of Medical and Health Research. 2018;4(7):21-5.

2. Dave $\mathrm{H}$, Trivedi N. Drug utilization pattern of antiepileptic agents among paediatrics epilepsy at a tertiary care teaching hospital of Gujarat: A cross sectional study. Indian Journal of Basic and Clinical Pharmacology. 2018;7(8):1606-11.

3. WHO. Essential Medicines and Health Products Information Portal, How to Investigate Drug Use in Health Facilities: Selected Drug Use Indicators EDM Research Series No. 007, Background on the development of drug use indicators. 1993. Available From: http://apps.who.int/medicinedocs/en/d/ Js2289e/1.1, 
4. WHO. Essential Medicines and Health Products Information Portal, How to Investigate Drug Use in Health Facilities: Selected Drug Use Indicators. EDM Research Series No. 007, Types of Indicators. 1993. Available From: http:// apps.who.int/medicinedocs/en/d/Js2289e/1.1,

5. Henry DRT, Sylvia A, Chidambaranathan S, Nirmala P. A prospective study of drug utilization pattern of anti-epileptic drugs and their adverse effects in a tertiary care hospital. International Journal of Current Pharmaceutical Research.2017;9(6):42-5.

6. Egunsola O, Choonara I, Sammons HM. Anti-epileptic drug utilisation in paediatrics: A systematic review. BMJ Paediatrics Open. 2017;1(1).
7. Bhojan C, Mehta PR, Sunny KN, Mathew AR, Jacob GR. A study on drug utilization evaluation of antiepileptics in pediatrics at a private corporate hospital. World Journal of Pharmacy and Pharmaceutical Science. 2017;6(2):542-9.

8. George J, Jose J, Kulkarni DA, Hanamantappa RR, Shalavadi CV. Evaluation of drug utilization and analysis of anti-epileptic drugs at tertiary care teaching hospital. Indian Journal of Pharmacy Practice. 2016;9(3):189.

9. Rishe W, Seifu MF, Gelaw BK, Gunasekaran T, Gebremariam ET, Mohammed MA. Drug use evaluation of antiepileptic drugs in outpatient epilepsy clinic of Bishoft General Hospital, East Shoa, Ethiopia. Indo Am J Pharm Res. 2015;5(2):951-62 